\title{
Medical Support In Chemical Operations
}

\section{INTRODUCTION}

\section{General}

Medical operations in a CW environment will be complex. In addition to providing care in protected environments or while dressed in protective clothing, medical personnel will have to treat chemically injured and contaminated casualties, sometimes in large numbers.

A mass-casualty situation occurs whenever the numbers or type of casualty exceeds the capabilities of the unit to treat and manage them in a normal fashion. An erroneous reaction to such a possibility is to assume that the problem is too great to cope with and preparations would be futile. Rather, the success of the medical department functioning effectively in a chemical war and treating successfully the maximum number of casualties will directly relate to the efforts made in advance to prepare for the possibility.

The doctrine, organisation and equipment available to handle chemical casualties will vary between countries and most particularly between Services, because of differences in military operational requirements. However, whatever the system, there will be a common set of problems that must be addressed in the management of chemical casualties - the clinical condition of the casualty will be the same or similar regardless of which Service he or she is a member, and because of similarities in the environment in which the casualty must be treated.

\section{Objectives of Medical Support in Chemical Operations}

The objectives are:

- To conserve the fighting strength.

- To continue to provide medical services and support to the maximum extent possible.

- To protect medical personnel from chemical injuries while handling contaminated casualties, or while working in contaminated areas.

- To minimise morbidity and mortality from conventional and chemical injuries.

- To avoid the spread of contamination into medical vehicles and facilities.

\section{Characteristics of Chemical Agents}

The physical characteristics of chemical agents will be described below for each class of chemical agent. These characteristics, the method of employment, and the meteorological environment in which they are used will have a major impact on the type and number of casualties produced.

Some agents, such as nerve agents, cyanide, and phosgene are highly lethal, and a large proportion of casualties may die unless care is given immediately after an attack. Other agents, such as sulphur mustard and Lewisite may be more incapacitating than lethal. The onset of symptoms will differ by type of agent and by route of exposure. Nerve agents and cyanide, especially by the inhalation route of exposure, are characteristically very rapid in onset of effects. However, mustard and phosgene may have a latent period of several hours between exposure and onset of symptoms. During the latent phase, the prognosis and future clinical course will not be apparent and the decision on whether to treat or evacuate will be difficult.

\section{Contamination Control}

One of the most difficult aspects of chemical warfare is that the chemical agents may persist in the environment for extended periods of time. This is especially true of agents such as the nerve agent VX, the mustards, thickened GB, or GD; they may remain as contact hazards for hours or days.

On the chemical battlefield, three types of environments may exist:

- An uncontaminated area where there are no chemical agents present.

- A contaminated area where chemical agents are present in a liquid state (and probably in a vapour state also) presenting a surface contact hazard.

- A vapour-only environment, for example, in a downwind hazard area.

Complete decontamination of a contaminated environment may be difficult or impossible. However it may be possible to achieve sufficient decontamination, particularly in small areas, to create a vapouronly hazard area. It may be possible to decontaminate equipment so that no further surface contact hazard exists, even though chemical agent vapours may continue to be off-gassed from agent adsorbed onto or absorbed into the surface (Figure 5).

In such environments, it may be possible 


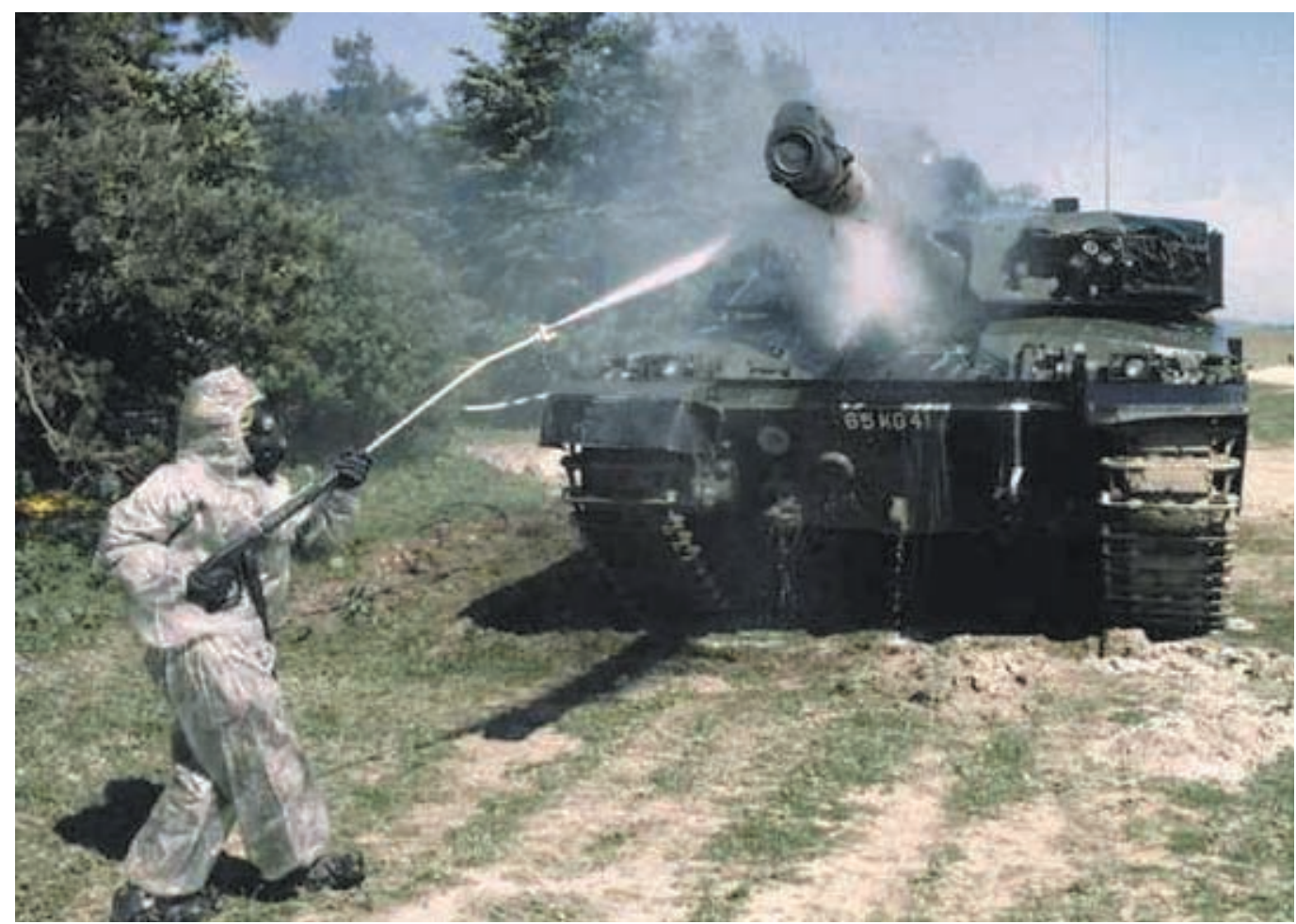

Fig 5. Decontamination of a vehicle with MPDS - Multi-Purpose Decontamination System.

to work without the full protective clothing ensemble, although respiratory and eye protection would still be required. This is because most agents in a vapour state penetrate through the skin very slowly.

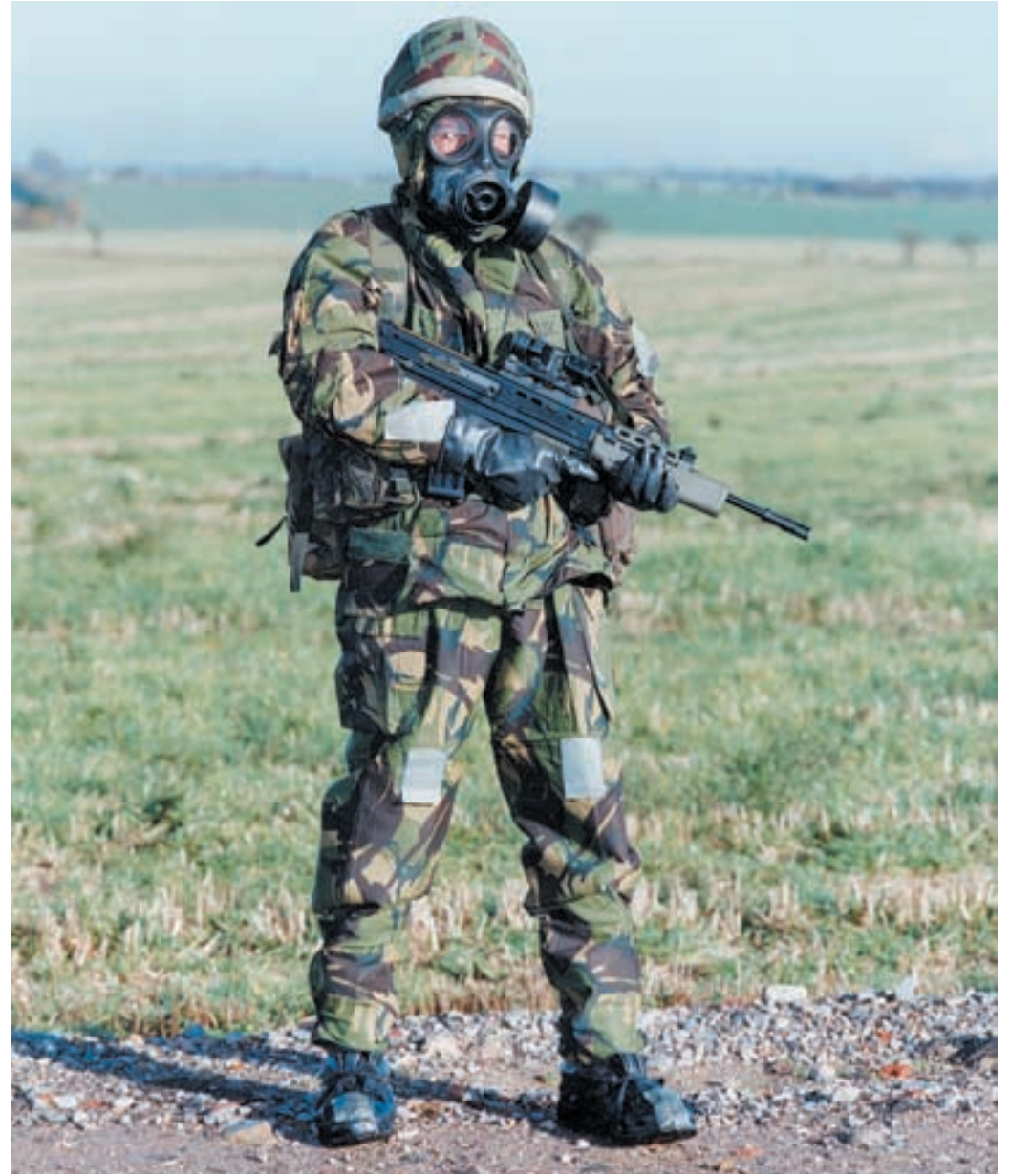

Fig 6. MkIV NBC suit and S10 Respirator; note the chemical detection papers on the legs and arms.
However, mustard at high vapour concentrations may still cause skin injury, particularly if the skin surface is wet or moist.

Where a liquid hazard exists, decontamination of skin and eyes must be accomplished quickly if it is to be effective. Chemical agents may penetrate or react with the skin and eyes within minutes, so successful decontamination must be carried out immediately after exposure. Once agent is decontaminated, or has been absorbed, no further risk of contamination exists. The casualty's body fluids, urine, or faeces do not constitute a CW hazard.

Individual and collective protection are the first line of defence against chemical agent contamination. Individual protection comprises the respirator and protective clothing including gloves and boots (Figure $6)$.

Full protective clothing is particularly important for persistent agents and agents that pose significant skin injury or skin penetration effects. For agents posing a respiratory or eye injury threat exclusively, the respirator would suffice. Individual protection imposes physiological and psychological stress on the individual, impairs communication, and reduces performance to a certain degree (depending on the individual's job performance requirements).

Collective protection is desirable, particularly for medical care. Adequate collective protection may not be possible, or may be difficult to achieve and will require personnel and equipment resources. In some instances, it may be feasible to establish a vapour-only hazard area, and work within that area at less than full individual 
protection, such as just using respiratory and eye protection. Limited medical care can be achieved in this manner, but full examination and definitive surgical treatment is impossible without full collective protection.

Collective protection provides the capability to medically manage severely toxic or injured decontaminated casualties in an environment where medical personnel are unencumbered by wearing individual protective equipment. Likewise, the casualties benefit from the capability of the medical unit to make full use of available medical equipment and procedures. A significant percentage of casualties (15-30\%) cannot be adequately treated in a contaminated environment without collective protection as their treatment requires the removal of their respirator.

In the presence of a CW threat, equipment and supplies should be kept in unopened, sealed or in covered containers until required for use. The use of chemical agent resistant material (CARM) will provide good protection against liquid contamination, but even the use of conventional tentage will significantly reduce contamination by a liquid agent for a limited period.

\section{Mass Casualties}

Chemical weapons may cause large numbers of casualties in poorly protected or untrained personnel. Experience in World War I showed that large numbers of casualties occurred most frequently with units that were surprised or inexperienced in chemical warfare. Such casualty surges will require careful pre-planning and training for medical units if they are to continue to operate efficiently.

All medical units must be prepared to receive mass casualties caused by, or contaminated with, chemical agents. Casualty sorting must take into account the possibility that some casualties may be contaminated. Some provision for emergency treatment of contaminated casualties needs to be made, since some critical care may be required before decontamination can be accomplished. Proper triage procedures are an essential element in handling large surges of casualties. With adequate advance planning and training, mass casualty situations can be managed and excessive morbidity and mortality reduced. Lack of such preparation, or a mistaken belief that such preparations are futile, are ingredients for disaster.

\section{Medical Decision Making}

Differential diagnosis is one of the first and most difficult aspects of managing chemical casualties. Unless it is known to which agent the casualty has been exposed, it may be difficult to establish a diagnosis with certainty. Further, the casualty may still be partially or fully encapsulated in a protective ensemble, and only the most simple signs and symptoms may be acquired.

Knowledge of the principal signs and symptoms is necessary to determine the clinical diagnosis. The rapidity of the onset of symptoms may be an important clue, for example in nerve agent poisoning or cyanide poisoning. In some instances, it is better to act rather than try to obtain a certain diagnosis, particularly if the condition of the casualty is serious and rapidly deteriorating. In forward treatment areas, the diagnosis should be kept as simple as possible, and be focussed to making decisions that will lead to some specific action or actions.

When chemical casualties are received at a medical unit, they may also have traumatic wounds or illnesses due to other causes. These patients must be managed to minimise the injuries resulting from chemical exposure without aggravating their traumatic wounds or illnesses.

\section{Triage}

Triage is one of the most important tools for handling combat casualties, particularly in mass casualty situations. Basically, it is a medical decision process used to arrange casualties in priority order to ensure the most effective use of limited medical resources and minimise morbidity and mortality. Triage is a continuous, ongoing process through the casualty care chain and should be utilised whenever casualties must be assigned priority for treatment, evacuation or decontamination. Triage decisions should be made by highly experienced personnel familiar with chemical and conventional injuries. Triage criteria should be determined in advance and practised. They must be relevant to the medical capabilities of the medical unit. The four standard NATO mass casualty triage categories, adapted for chemical casualties, are as follows:

- Immediate treatment (TI). This includes those requiring emergency life saving treatment. Treatment should not be time consuming or require numerous, highly trained personnel, and the casualty should have a high chance of survival with therapy.

- Delayed treatment (T2). The general condition permits some delay in therapy although some continuing care and relief of pain may be required before definitive care is given.

- Minimal treatment (T3). This includes those with relatively minor signs and symptoms who can care for themselves or who can be helped by untrained personnel.

- Expectant treatment (T4). This group is comprised of patients who have life threatening conditions beyond the treatment capabilities of the medical unit; their treatment would be time consuming, 
require numerous highly trained people and would have a low chance of success. It must be noted that the decision to place a casualty in the Expectant category is not necessarily a decision to render no therapy. Rather, the triage categories determine the priority in which casualties are treated.

Chemical poisoning, besides being difficult to treat in itself, will complicate the therapy for other conditions. The addition of antidote therapy may further complicate management of other conditions requiring drug therapy, for example, use of muscle relaxants for surgery or the use of analgesics. Some of these drug interactions are currently unknown, and the medical staff must remain alert for unusual reactions to otherwise common therapy on the battlefield.

\section{CASUALTY MANAGEMENT PHASES}

\section{General}

Field Medical Operations

Field medical operations are conducted with several echelons of care, with increasing capabilities, and more sophisticated equipment towards the rear. The most forward medical support is usually provided by enlisted medical personnel with limited equipment, drugs, and medical capabilities.

\section{Far Forward Treatment}

Major advances have been made in casualty survival by advances in medical and surgical capability, and most importantly by advances in rapid evacuation and early stabilisation of casualties. On the chemical battlefield, early treatment and stabilisation will be particularly critical, since the lethal agents have very rapid onset of severe, life threatening effects. This means that far forward treatment, often by non-medical personnel, will be of even greater importance than in conventional warfare.

\section{Casualty Care Systems}

A specific example of a casualty care system is described in AMedP-7(A) - Concept of Operations of Medical Support in a Nuclear, Biological and Chemical Environment. Because the mission requirements of each Service differ markedly, the organisation of medical support, the types and amount of medical resources at the echelons, and the evacuation distances between echelons will differ greatly. Further, there will be other national differences, such that the description of a particular system will not coincide with other national or Service systems.

When the necessity of certain functional capabilities to handle different systems is considered, important similarities between the different systems can be identified. Nine functional phases of casualty care have been identified. Not every casualty will pass through all phases. Further, some phases such as evacuation, may be performed several times. Although the phases are arranged in order below, the exact temporal order may vary from system to system, or be modified by force of circumstances. The first three phases, pre-attack, self aid and buddy aid will be carried out by non-medical personnel in the units themselves. The remainder of the phases will generally be carried out by medical personnel and units.

\section{Phase I - Pre-Attack}

The steps taken before an attack occurs will be the most important in determining how many and how severe the casualties will be. The protective mask and clothing are the first line of defence. Some nations (such as the UK) have pre-treatments available for protection against certain chemical agents. Training will be essential to maximise protection of personnel and equipment. With multiple dose pre-treatments, strict discipline to ensure proper use will be necessary. The immediate commander exercises primary responsibility for ensuring that all necessary steps are taken. Medical personnel have a staff advisory role to the commanders in assisting them on matters of medical importance. For instance, commanders need to be advised of the physiological stress characteristics of the protective ensemble and how performance capabilities may be altered. The relationship between environmental temperature and heat stress needs to be emphasised, especially in training situations, to avoid unnecessary heat casualties. Medical units will generally follow the same training and procedures for protecting themselves as do the non-medical units. An example of guidance for the prevention of heat casualties is given later in this edition of the Journal.

\section{Phase II - Immediate Post- Attack/Self Aid}

The goal in this phase is to:

- protect oneself from agent exposure during and immediately after an attack.

- stop any further exposure.

- initiate immediate therapy if a significant exposure has occurred.

Since it is by definition "self aid," it is carried out only by personnel still capable of functioning. For agents with rapid onset, some personnel may not have time to take any steps before they are severely incapacitated and will not pass through this phase. Since personnel in this phase will still be able to function to a certain degree, it is important that any treatment that they take should not be incapacitating in itself. Some individuals will take such self aid mistakenly when they have not had a significant 
exposure, or it may even be taken deliberately. Since the preservation of the unit effectiveness is most important at this point, additional casualties from the antidotes must be avoided.

The specific antidotes available for self care are discussed in the chapters for the different classes of agents, and are further prescribed in national and service doctrines. The specific steps in self-administration of the antidotes are likewise part of national and service doctrine and training. A critical factor in use of self aid antidotes is clearly defining the specific conditions under which they will be taken. Most commonly, they are taken when the individual notices a specific set of symptoms, characteristic for the agent. Additionally, self decontamination kits and their use are described in national and service doctrine.

\section{Phase III - Buddy Aid}

Buddy aid is the care given by non-medical personnel to casualties who are not able to care for themselves. Incapacitation of various degrees is the marker differentiating between self care and buddy care.

Many units do not have medical personnel assigned or attached, or the medical personnel may be casualties. Since immediate care is often so important in treating chemical casualties, buddy care will be the determining factor in the success of treatment. Unit commanders must take considerable care to ensure that all personnel have adequate training to perform buddy care for chemical agent casualties. Such training is essential since the normal instinct of soldiers to help one another may be hampered by the inability in protective clothing to recognise that help is needed. Medical personnel may assist commanders in providing training.

Since the numbers of medical personnel are limited, particularly in forward units, commanders may wish to have a few nonmedical personnel trained to a higher level of medical proficiency than would be feasible for all personnel. This could be valuable in resuscitation of nerve agent casualties for example, where the procedures are more complex. Such trained personnel would also provide back-up for medical personnel who may become casualties.

The antidotes available for buddy care will usually be the same as those provided for self aid. Since the casualty will be already incapacitated, the concern for further incapacitation from antidotes no longer applies, and further or higher doses of antidotes may be given if available. The individuals providing buddy care should not use their own antidotes to treat a casualty since they may need it themselves, but should use those belonging to the casualty, or any others available.

Commanders will have to exercise some control on buddy care, so as not to compromise mission accomplishment, but must also recognise their exclusive responsibility for the welfare of the casualties while they are still in the commanders' units. Manpower intensive procedures such as resuscitation must be applied judiciously, and only to those likely to benefit in order to avoid tying up too many personnel. Similarly, casualty evacuation out of the unit often requires the unit's own personnel initially and must be tightly controlled to retain personnel within the unit. Again, unit survival must be the overriding consideration.

\section{Phase IV - Initial Medical Care}

Initial medical care is the first care given by medical personnel. Although for administrative reasons medical care is sometimes defined as beginning when a casualty is treated by medical personnel, from a functional consideration medical care should be a continuous process, and this phase is a continuation of care given in preceding phases.

The goals of the initial medical care are to return to duty promptly all personnel still effective, and to stabilise and prepare for evacuation those casualties who require further medical care. Even though the medications, equipment, and medical personnel resources available far forward are limited, this phase will still be highly critical for successful outcome. With certain agents, casualties reaching this point may be severely incapacitated. Triage will be important in determining priorities of care and evacuation.

\section{Phase V - Life \\ Support/Stabilisation}

Given the rapid onset and severe course of poisoning by some of the chemical warfare agents - nerve agents in particular consideration for life support of vital, cardiovascular and respiratory function will often be required. Other conditions such as haemorrhage or shock from conventional wounds will also require immediate care. The ability to successfully manage these conditions will depend on the resources available at the various echelons. Triage criteria may dictate that some of these casualties will have a low priority of care. However, it is vital to make some effort to stabilise a casualty before evacuation to higher echelons and some effort at stabilisation should precede time consuming efforts such as full casualty decontamination. Therefore, some means of handling severe casualties should be incorporated early on in the system of managing casualties at each echelon. Haemorrhage, severe respiratory distress, cardiovascular collapse, shock, and seizures are among the conditions requiring prompt attention. 


\section{Phase VI - Evacuation}

Evacuation of chemically injured casualties entails more than transportation. Monitoring is important to ensure that the casualty's condition is not deteriorating. Some provision for in-transit care will also be critical. Since some casualties may be contaminated, the casualty evacuation system must be organised to minimise the spread of contamination. Since mass casualties may occur, and the number of medical vehicles may be inadequate to meet the increased load, unit commanders need to have contingency plans to supplement medical vehicles for casualty evacuation, or be prepared to retain casualties within their units for longer periods of time. Aeromedical evacuation is desirable when feasible and available, but the combat situation, the chemical environment and the possibility of contaminating helicopters may preclude their use far forward, in the initial stages of evacuation.

\section{Phase VII - Casualty Decontamination}

The goal of casualty decontamination differs from personal and unit decontamination. In addition to preventing exposure of the agent, casualty decontamination also has the aim of preventing exposure of medical care personnel and facilities to contaminated casualties. The requirement for casualty decontamination will be a function of the agent used, environmental factors, and particularly time. Liquid chemical agents on the skin may react with it, or penetrate it rapidly. Some method of monitoring contamination would be valuable in determining the degree of decontamination required (Figure 7 ).

It is imperative that at least limited decontamination is performed as soon as possible. This will diminish the chance of re- contamination of the casualty, or contamination of medical personnel and facilities from any agent left on the clothing or equipment. Given the time it takes to evacuate casualties, the quantity of liquid agent on the skin or clothing will have diminished or even disappeared due to evaporation. Careful removal of the clothing and equipment, with spot decontamination of skin areas that may be at risk of recontamination when the clothing is removed, may often be just as effective as full decontamination; it can be accomplished more quickly and with fewer personnel. Protecting the wound from any further contamination with protective dressings is desirable. Further management of wounds should follow normal treatment procedures.

The hazard of off-gassing and further contamination from clothing and equipment removed from contaminated casualties requires that these items be disposed of properly. Several methods may be utilised for this purpose, such as impermeable bags or containers, or bleaching powders. Disposal sites for these items must be marked in accordance with the standard NATO markings.

\section{Phase VIII - Definitive Care}

Specific treatment of the chemical casualty should be initiated as far forward as possible. It may occur across several echelons of care, involving increasingly sophisticated medical treatment as the casualty is evacuated to the rear.

\section{Phase IX - Disposition}

Following successful medical intervention, it must be decided whether a casualty should be returned to duty, held, or evacuated further to the rear for further treatment and convalescence. For casualties with minor exposures, it is desirable to return them to

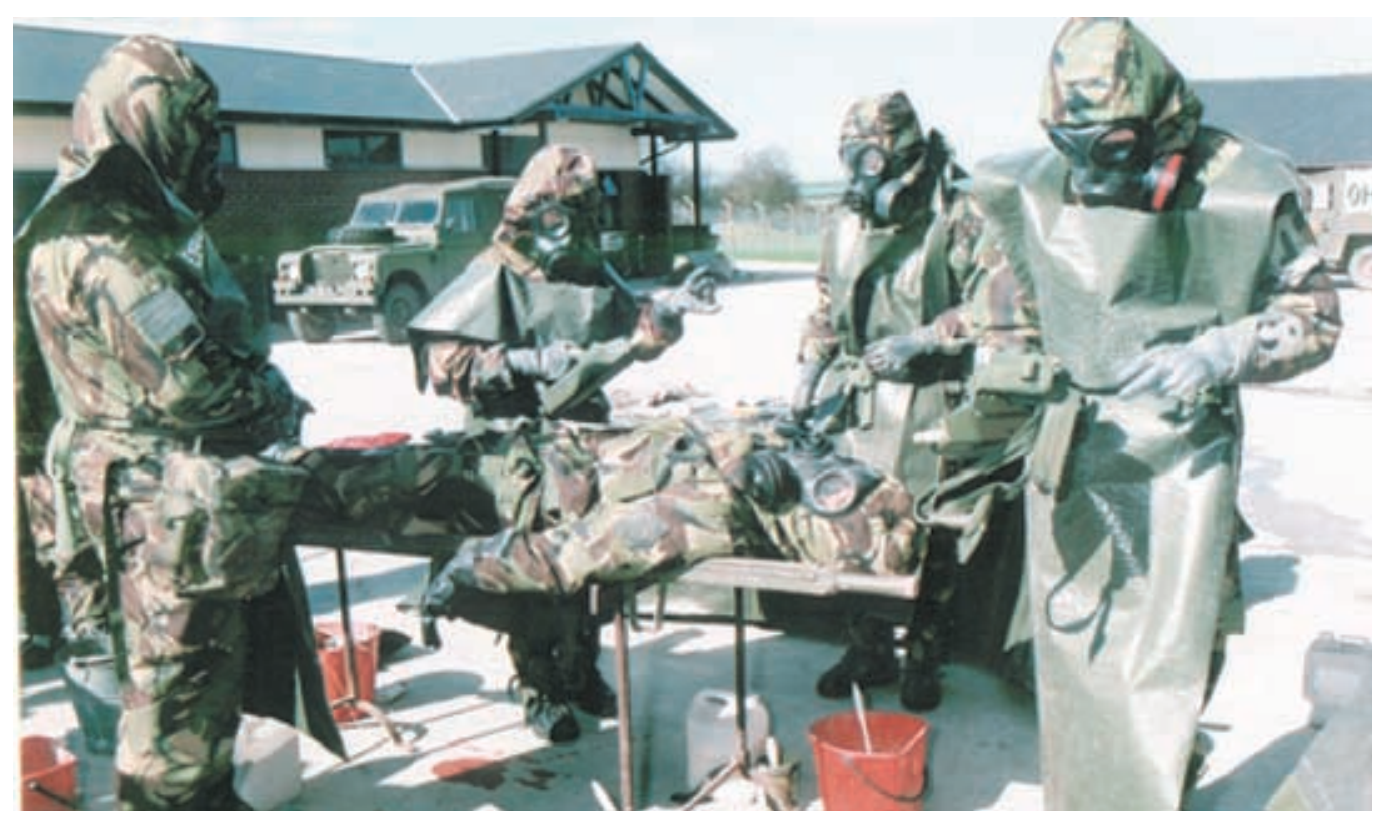

Fig 7. Monitoring contamination on a casualty with the Chemical Agent Monitor (CAM). 
duty as soon as possible, and as far forward as possible, although this is not always operationally feasible. For casualties with severe poisoning, the course may be prolonged, and a long convalescence may be expected. The disposition of injuries from sulphur mustard is dependent not only on the extent of injury, but also on the site of injury (discussed below). Care must be exercised in early mustard or phosgene injuries not to confuse the latent period with absence of injury. Nerve agent casualties with depleted cholinesterase levels are likely to be more susceptible to subsequent poisoning from nerve agents until their cholinesterase levels return to normal.

\section{COMBINED INJURIES}

\section{Introduction}

Contamination of traumatic wounds by chemical warfare agents presents specific medical problems. Nerve agents and vesicants, especially if thickened, may persist within wounds and present a hazard to surgical teams during primary surgery. The potential threat to the casualty with a combined injury depends on the quantity and type of agent that exists within the wound, and on the amount remaining in the wound. Agents may be absorbed rapidly but some remain within the wound for some time, particularly on foreign bodies such as clothing. The amount and form of contaminated cloth in wounds and the type of agent then determine the persistence of the agent within the wound. It must be assumed that all wounds are contaminated in a chemical environment.

\section{Severity of Effect}

The severity of toxic effects depends on a number of factors:

- Type of agent: nerve agents or vesicants (thickened or unthickened, liquid).

- The extent of the contamination of the wound. Agent is usually carried into the wound by contaminated clothing, or may directly contaminate a previously clean wound.

- The nature of the wound - high/low energy transfer, perforating or retained projectile; entry/exit wound dimensions.

\section{Early Treatment}

Capabilities for prompt casualty (including wound) decontamination and systemic treatment must be provided as far forward as possible. Subsequent definitive wound decontamination is achieved by surgical treatment.

\section{Self/Buddy Aid}

a. Carry out combat first aid procedures, including antidote treatment.

b. Emergency wound decontamination:

- Skin surrounding the wound should be decontaminated.

- If an approved wound decontaminant is available use generously in the wound (such as the MK 291).

- Apply dressing.

- Restore the integrity of the Individual Protective Equipment.

\section{Role 1 Medical Treatment}

a. Carry out basic and advanced life support, including continued antidote treatment.

b. Expose to treat decontamination or definitive casualty decontamination as necessary according to triage category.

c. Irrigate the wound with a chemical neutralising solution (0.3-0.5\% hypochlorite solution). The solution should be given two minutes to act before copious water irrigation of the wound.

\section{Role 2 Medical Treatment}

a. Life-saving treatment, antidotes, etc, as required to stabilize the patient.

b. Definitive casualty decontamination if not previously accomplished.

c. Further wound decontamination if clinically required or if chemical agent is detected.

\section{Role 3 and 4 Definitive Wound Treatment}

a. All dressings may be contaminated, and should be removed and disposed of in a concentrated hypochlorite solution or in a vapour proof container.

b. The wound should be irrigated with a wound neutralising solution, the solution should be given two minutes to act, then copiously irrigate the wound with water.

c. The wound should be enlarged, debrided adequately and left widely open.

d. The wound should be explored with surgical instruments rather than fingers (a "no touch" technique should be used) since a contact hazard may remain until all contaminated tissue and foreign bodies are disposed of promptly and properly.

e. Surgical gloves give very little protection against chemical warfare agents. Protection of staff can be enhanced by the use of thin butyl rubber gloves or the use of double latex surgical gloves, dipped frequently in wound decontaminant solution and changed when contact or puncture is suspected.

f. All operating room staff must wear eye protection to protect against chemical warfare agent splashes.

g. Used surgical instruments should be immersed in the wound decontaminant solution when not in use during the operation.

h. Deep or complex wounds may require repeated irrigation since exploration may uncover further contamination.

i. Automatic decontamination devices can be used for evaluation of contamination 
remaining in the wound. With deep or complex wounds, it may be used repeatedly.

j. No active decontaminant should be used in the eye or brain. Saline, water or dilute bicarbonate should be used.

$\mathrm{k}$. The abdomen and thoracic cavity should be washed out with saline because of the possibility of irritation and reaction. Saline irrigation may cause a vapour hazard and an automatic device should be used constantly. Irrigation fluid is potentially contaminated; it should be sucked out with a larger bore sucker and disposed of in a concentrated hypochlorite solution rather than mopped out with swabs.

\section{Risk to Casualty and Treatment Provider}

The true risk to the casualty and surgical teams will depend on the type, quantity and persistence of the chemical warfare agent in the wound. The contamination density of the agent on clothing and the amount of clothing transferred into the wound by the munition fragment or bullet have been shown to define the quantity and persistence of agent within the wound. This is also influenced by the type of wound, and the delay between contamination of the wound and wound decontamination/excision, during which agent may have been absorbed systemically, bound, or hydrolysed.

- Thickened Nerve Agent. Most casualties with high-energy wounds or multiple lowenergy wounds would absorb a lethal dose rapidly through contaminated clothing and die within minutes. Persistence of agent at surgery would therefore rarely be an issue. With a single small fragment wound, severe acetylcholinesterase depression would be likely with signs of nerve agent poisoning and risk of mortality. A significant amount of agent could persist in such a wound but there is unlikely to be a significant vapour hazard.

- Unthickened Nerve Agent. With large fragment high-energy and low-energy wounds, casualties would have significant acetylcholinesterase depression but the majority are likely to survive. Persistence of these agents depends on the amount of cloth contamination - large fragments of cloth would retain significant quantities of agent. Although nerve agents cause their toxic effects by their very rapid attachment to the enzyme acetylcholinesterase, they also react with other enzymes and tissue components. The blood and necrotic tissue of the wound will "buffer" nerve agents. Nerve agent that reaches viable tissue will be rapidly absorbed, and since the toxicity of nerve agents is high, it is unlikely that casualties who have much nerve agent in a wound will survive to reach medical treatment. VX is absorbed less quickly than other nerve agents and may persist in the wound longer than other nerve agents.

- Sulphur Mustard. Mustard converts to a cyclic compound within minutes of absorption into a biologic milieu, and the cyclic compound rapidly (minutes) reacts with blood and tissue components. These reactions will take place with the components of the wound - the blood, the necrotic tissue, and the remaining viable tissue. If the amount of bleeding and tissue damage is small, mustard will rapidly enter the surrounding viable tissue where it will quickly transform and attach to tissue components (and its biological behaviour will be much like an intramuscular absorption of the agent). Vapour hazard from the wound will be low.

\section{Release of vapour}

The risk from vapour from chemically contaminated munition fragments and cloth in wounds is very low and thought to be not significant. There is no vapour release from contaminated wounds without foreign bodies. Release of vapour from a wound during surgical exploration will be negligible (or zero). No eye injury will result from any of the agents, however eye protection should be worn to protect from a splash during irrigation. A chemically protective mask/respirator is not required for surgical personnel.

\section{Drug Interactions}

The effect of poisoning by chemical warfare agents and the effect of drugs used in the treatment of such poisoning must be considered in the treatment of casualties who are suffering from conventional wounding (even if the wounds were not contaminated). A summary of possible interactions is listed in Table 1.

Table 1. Potential Interactions of Chemical/Conventional Injuries.

\begin{tabular}{|ll|}
\hline Chemical Agent Group & Potential Interaction \\
\hline $\begin{array}{l}\text { Nerve agents } \\
\text { (carbamate pre-treatment) } \\
\text { (atropine) }\end{array}$ & $\begin{array}{l}\text { Relaxants in anaesthesia } \\
\text { Blood loss } \\
\text { Shock }\end{array}$ \\
Vesicants & $\begin{array}{l}\text { Slow healing of wounds } \\
\text { (mustard and arsenicals) }\end{array}$ \\
& $\begin{array}{l}\text { Haematopoietic depression } \\
\text { Infection more likely }\end{array}$ \\
Lung Damaging Agents & $\begin{array}{l}\text { Resuscitation } \\
\text { Blood loss } \\
\text { Shock (latent period may be } \\
\text { shorter) }\end{array}$ \\
\hline
\end{tabular}

\section{OTHER CONSIDERATIONS}

\section{Collective Protection}

Collective protection greatly enhances the treatment of casualties in a contaminated environment; $15-30 \%$ of casualties cannot be adequately treated without removal of their respirators. 
Table 2. Heat Casualty Prevention Guide.

\begin{tabular}{|c|c|c|c|}
\hline $\begin{array}{c}\begin{array}{c}\text { Heat } \\
\text { Condition } \\
\text { (category) }\end{array}\end{array}$ & $\begin{array}{l}\text { WBGT index }{ }^{\star} \\
\left({ }^{\circ} \mathbf{C}\right)\end{array}$ & $\begin{array}{l}\text { Water intake } \\
\text { (L per hour) }\end{array}$ & $\begin{array}{c}\text { Work/rest } \\
\text { cycle } \\
\text { (minutes) }\end{array}$ \\
\hline 1 & $\begin{array}{c}25.5 \\
\text { to } \\
27.6\end{array}$ & At least 0.45 & Continuous \\
\hline 2 & $\begin{array}{c}27.7 \\
\text { to } \\
29.3\end{array}$ & At least 0.45 & $50 / 10$ \\
\hline 3 & $\begin{array}{c}29.4 \\
\text { to } \\
31.0\end{array}$ & At least 0.9 & $45 / 15$ \\
\hline 4 & $\begin{array}{c}31.1 \\
\text { to } \\
32.1\end{array}$ & At least 1.4 & $30 / 30$ \\
\hline $5^{\star \star}$ & $\begin{array}{c}32.2 \\
\text { and } \\
\text { above }\end{array}$ & More than 1.8 & $20 / 40$ \\
\hline
\end{tabular}

*Wet bulb gradient temperature. Individual protective equipment or body armour adds at least $6^{\circ} \mathrm{C}\left(10^{\circ} \mathrm{F}\right)$ to the WBGT index. ${ }^{*}$ Suspend physical training and strenuous activity. If operational mission (non-training) mission requires strenuous activity, enforce water intake to minimise expected heat injuries.

\section{Head Wounds}

Head wounds, after being attended to and dressed, will necessitate the casualty being evacuated in a casualty bag or half bag or hood. In emergency, the casualty's head may be protected in a pervious blouse from a spare protective suit.

\section{Heat Stress}

The use of individual protective equipment and casualty bags imposes a significantly

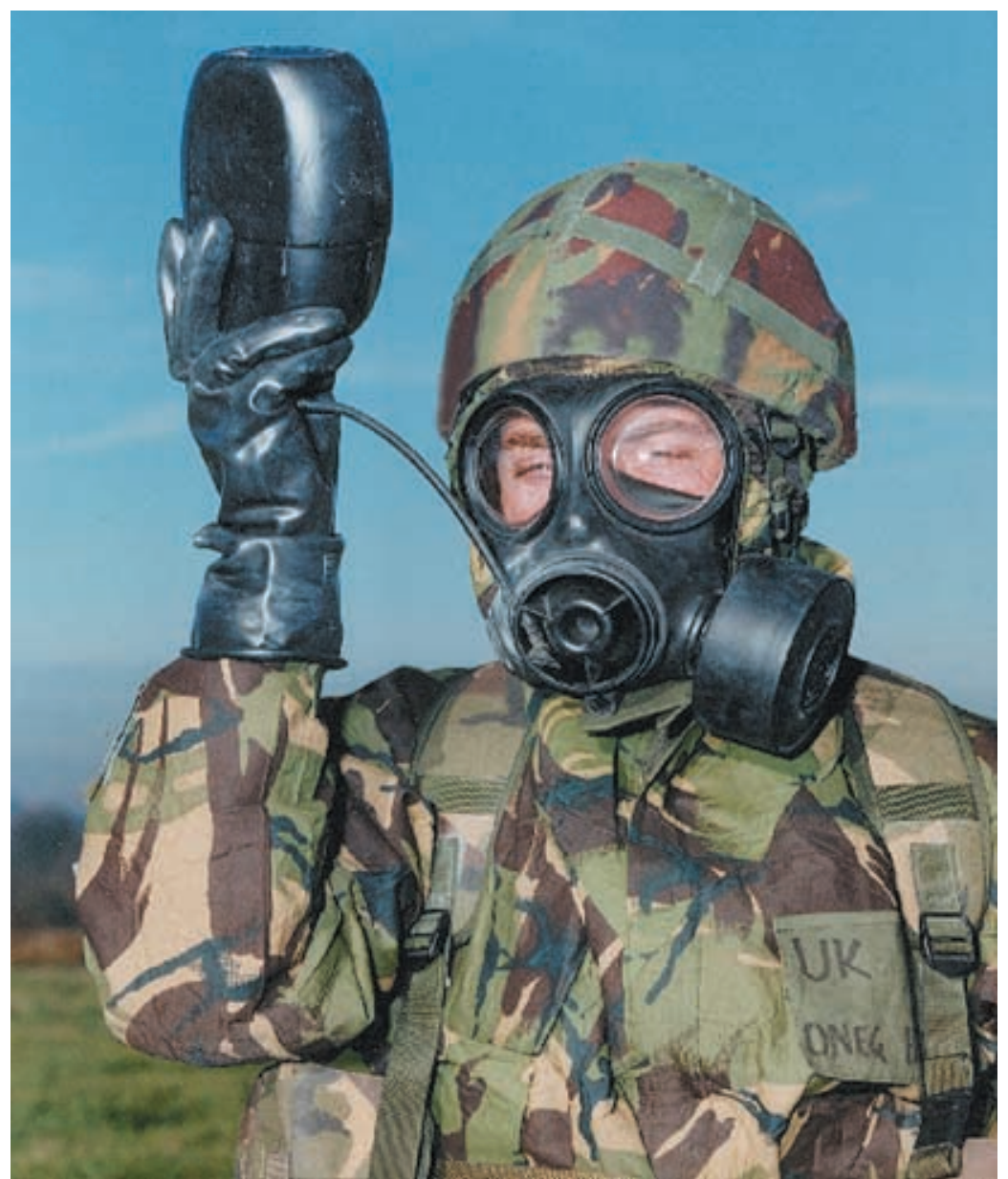

Fig 8. Personnel in Individual Protectived Equipment need fluids greater heat stress upon the individual. In warm environments and at moderate work rates personnel are susceptible to heat injury. The medical officer's responsibilities may include providing advice to commanders about work/rest cycles and of the need for increased fluid intake. Medical attendants need to be especially aware of the need to replace fluids in casualties wearing individual protective equipment (Figure 8 ).

Protective equipment makes monitoring casualties difficult and a high index of suspicion for heat stress must be maintained at all times. Table 2 may be applied as guidance for the prevention of heat casualties in acclimatised individuals. In situations where work is heavy or prolonged, the risk of heat injury exists at wet bulb gradient temperatures (WBGT) below $78^{\circ} \mathrm{F}$ $\left(25.5^{\circ} \mathrm{C}\right)$.

\section{Further Reading}

Medical Manual of Defence Against Chemical Agents (JSP 312). Publisher: Her Majesty's Stationery Office, 1987. 